\title{
Assessing the Technical Efficiency of Public Hospitals in Cameroon: An Application of Data Envelopment Analysis (DEA)
}

\author{
Prof Molem Christopher, Sama \\ University of Buea \\ molem.sama@gmail.com
}

\author{
Beri Parfait, Bihkongnyuy \\ University of Buea \\ parfaitberi@gmail.com
}

\begin{abstract}
This study assesses the technical efficiency using a panel data set (obtained from the National Institute of Statistics) comprising 109 public health facilities belonging to the National Health System of Cameroon for the period 2002-2003.Data Envelopment Analysis (DEA) was employed to estimate the efficiency scores. The analysis indicated that there exist high levels of inefficiency within public hospitals in Cameroon. The inefficiencies have resulted to high operating costs in the Cameroon public health system. Rural health facilities were the least efficient compared to semi-urban and urban health facilities while Integrated health Centres were highly inefficient than Sub-divisional and District hospitals respectively. It was then recommended that the Ministry of Public Health should put in more efforts geared towards ensuring consistent increase in the overall efficiency by developing policies and procedures to control the wastage of valuable input resources and recruiting more qualified medical personnel. While the government continue to explore other alternative health financing options as indicated in the Vision 2035, efficiency improvement should be considered as one of the strategies for mobilizing more domestic resources.
\end{abstract}

Keywords: Technical Efficiency, Data Envelopment Analysis (DEA).

\section{INTRODUCTION}

In an era of resource constraints, the need for hospital managers and health administration personnel to design different methods of analysing hospital performance has become a ubiquitous phenomenon. Ranking efficient hospitals over inefficient ones provides a yardstick for hospital managers to ascertain and cut down potential inefficiencies, and provide health administration authorities with measures that may be used to reward the efforts of good managers (Álvaro \& Fique, 2011). The quest for better performance of hospitals has led to an extensive literature on health care provision in most national health systems and on efficiency analysis in particular.

Many international institutions especially the World Health Organization (WHO) and the World Bank, have recommended that countries should adopt universal health care coverage to ensure good health to its citizens, consistent with the fundamental human right of life (Amy \& Robert, 2006). Hernandez \& Miguel (2014) suggested that "improving the performance of health systems in low- and middle-income countries (LMIC) can help redress health iniquities and make the right to health a reality for vulnerable populations". The World Health Assembly (2000) has also emphasized that "people's health and well-being depend essentially on the performance of the health systems that serve them" (Nazgul, 2011).However, healthcare systems especially in the case of developing countries are faced with a major challenge of resource scarcity as they often have insufficient resources to respond to all health problems.

Over the years, more emphasis in Cameroon has continuously been laid on increasing budgetary allocations to the sector while neglecting an assessment of the corresponding improvements in health outcomes. Further, an increase in the allocation of resources for healthcare often come at the expense of other national priorities including education, housing, water, national defense etc. Proper management of limited healthcare resources then becomes fundamental if the system has to meet up with its objective of improving the health of the population. It has also been shown in the literature that public health spending may have insignificant impact on the population's health status; because of the failure of health resources to translate into improved services (Njong \& Ngantcha, 2013). Their analyses based on the first Public Expenditure Tracking Survey data of Cameroon in 2004 also revealed that $18.8 \%$ of the actual budget allocations of decentralized health services in the Ministry of Public Health in Cameroon do not reach them and health centres which are the most prominent in 
providing healthcare receive only $26.4 \%$ of their actual budgets contained in the recurrent expenditures of the decentralised health services.

The existing evidence suggests there is inefficiency in the public health sector in Cameroon (Njong\&Ngantcha, 2013; Nguenda, 2012; Sjaak, 1982). Notwithstanding, the actual level of efficiency of public hospitals in Cameroon is still not known and the way efficiency vary by type of health facility (Sub Divisional Medical Centres, Integrated Health Centres, District Hospitals) and location(Urban, Semi-Urban and Rural)is yet to be determined. It is for this reason that the paper is set out to determine the level of technical efficiency of public hospitals in Cameroon. The remainder of this paper is organized as follows. Section 2 reviews the literature. Section 3 details the methodology. Section 4 presents the results and Section 5 concludes.

\section{LITERATURE REVIEW}

According to Coelli (1996), modern efficiency measurement begins with Farrell (1957) who drew upon the works of Debreu (1951) and Koopmans (1951) to define a simple measure of firm efficiency which could account for multiple inputs. He suggested that the efficiency of a firm consist of technical efficiency which reflects the ability to obtain maximal output from a given set of inputs and allocative efficiency which reflects the ability of a firm to use the inputs in optimal proportions given their respective prices. These two measures can then be combined to provide a measure of total economic efficiency. In economic terms, the concept of efficiency can be defined as the relationship between scarce factor inputs and outputs. It examines how well scarce resources are converted into outputs. Health services are interventions provided to improve health for people in different health systems. This reflects the primary objective of health care from a social perspective. In this context, health care efficiency refers to how well health care resources are used to obtain health improvements (Peacock et al., 2001).

Technical efficiency seeks to identify in physical terms, the best possible combination of factor inputs to produce a given output (Nunamaker, 1985). In a health system, this implies that technical efficiency refers to the physical relation between resources (costs, in the form of labour, capital, or equipment) and health outcome (numbers treated, waiting time, etc.) or final health outcomes (lives saved, life years gained, quality adjusted life years [QALYs]). Nunamaker describes technical efficiency as a measure of the ability of a Decision Making Unit (DMU) to avoid waste by producing as much output as input usage will allow, or using as little input as an output level will allow. This definition is however specific to the one most commmonly used in sectors such as agriculture and manufacturing where they have clearly defined outputs unlike in the health sector where intermediate outputs are often used as proxies for the final output that people seek to achieve(health). Technical efficiency in health economics therefore assesseswhether healthcare interventions for particular health units (such as the treatment of illnesses) are each performed with the least amount of inputs. A technically efficient position is achieved when the maximum possible improvement in outcome is obtained from a set of resource inputs.

Different doctrines have emerged in the last three decades that explain efficiency of public health facilities. Agency and property-rights theories provide different explanations for a common outcome in the hospital sector. "They often hypothesize that Private for-profit ownership is better to public and private non-profit ownership because private for-profit ownership is associated with a higher productive efficiency" (Meryem, 2000). These theories purport that differences in efficiency emerge as a consequence of the variance in objectives, incentives, and control mechanisms between ownership types, location etc. Existing theoretical evidence from both property rights and agency theories therefore seem to suggest that private institutions produce more efficiently than their public counterparts.

Hollingsworth (2008) reviewed literature on frontier efficiency measurement techniques in healthcare from the early 1980 s up to mid-2006 and found a total of 317 published studies, $80 \%$ of which made use of non-parametric DEA while most of the other studies used parametric stochastic frontier analysis (SFA). He reviewed studies on efficiency differences of hospital ownership and found 39 studies and concluded that public hospitals in Europe and the United States appear to be more efficient than their private for profit and non-profit counterparts. This has been supported by the works of Ozcan, Luke, and Hakseve (1992); Burgess and Wilson (1996); Koop, Osiewalski, and Steel (1997); Chirikos and Sear (2000). However, other empirical works contend that public hospitals are generally less efficient than private hospitals as seen in Wouters (1993); Zuckerman, Hadley, and 
Iezzoni(1994); Ferrier and Valdmanis(1996); Chang, Chang, Das, and Li (2004), Annika, (2008); while a number of other studies have found no significant variation in efficiency between public and private hospitals, Sari (2003) and Tiemann\&Schreyögg(2009). A lot is yet to be uncovered and the need for more empirical works on efficiency is therefore required to contribute to the existing literature.

\section{Methodology}

This study employs the method of Data Envelopment Analysis (DEA) to estimate the technical efficiency of public hospitals in Cameroon. DEA is a nonparametric technique originally developed by Chames, Cooper and Rhodes (1978) to evaluate the performance of non-profit and public sector organizations often referred to as Decision Making Units (DMUs) in efficiency studies. These DMUs perform the same function by employing multiple inputs to produce multiple outputs. This method employs linear programming in its methodology that makes it a particularly powerful technique when compared with other productivity measurements. DEA is most important in situations where there are multiple outputs and inputs, which cannot be readily analysed with other techniques like ratios, and where the number of DMUs being evaluated is so numerous that management cannot afford to evaluate each unit in depth. Mathematically, when a DMU employs only one input and produce a single output, efficiency is simply measured by;

Efficiency $=\frac{\text { Output }}{\text { input }}$

Most DMUs however employ more than one input in the process of their production and also produce multiple outputs. The equation specified above is usually then modified to consider the multiple inputs and output characteristic of the DMU by reducing these inputs to a single input and output as presented below (Meryem, 2000);

Efficiency $=\frac{\text { Weighted sum of Outputs }}{\text { Weighted sum of inputs }}$, the maximisation problem is then set as follows,

$\operatorname{Max} h_{c=}=\frac{\sum_{r=1}^{S} u_{r} y_{r 0}}{\sum_{i=1}^{m} v_{i} x_{i 0}}$

Subject to:

$$
\frac{\sum_{r=1}^{s} u_{r} y_{r j}}{\sum_{i=1}^{m} v_{i} x_{i j}} \mu_{r}, v_{r} \geq 0, r=1, \ldots s ; i=1, \ldots m
$$

\begin{tabular}{llll}
\hline $\mathrm{j}=$ & $\begin{array}{l}\text { Number of DMUs being compared in } \\
\text { the DEA analysis }\end{array}$ & $y_{r j}=$ & Amount of output $\mathrm{r}$ from DMU $\mathrm{j}$ \\
$\mathrm{DMUj}=$ & $\begin{array}{l}\text { Decision Making Unit number } \mathrm{j} \\
\text { Efficiency score of the DMU being } \\
\text { evaluated by DEA }\end{array}$ & $x_{i j}=$ & $\begin{array}{l}\text { Amount of input } i \text { to DMU } j \\
\text { Number of inputs used by the } \\
h_{c}=\end{array}$ \\
$r=$ & $\begin{array}{l}\text { Number of outputs generated by the } \\
\text { DMUs }\end{array}$ & $\begin{array}{l}\text { DMUs } \\
\text { Coefficient or weight assigned by }\end{array}$ \\
$v_{i}=\quad \begin{array}{l}\text { Deficient or weight assigned by DEA } \\
\text { to input } i\end{array}$ & & \\
\hline
\end{tabular}

DMUs with an efficiency score of 1 are qualified as best "practice frontier" and thus provide a benchmark which allows a reference for judging other DMUs that obtain efficiency scores of less than one.

One major problem often faced by researchers with the formulation stated above is that the relative weights needed to value inputs and outputs are not often available. Without these weights, ratio analysis may be only marginally helpful and possibly misleading in multiple-output, multiple-input applications. This inability to identify relative weights for different inputs and outputs limits the ability to use operating ratios to gain insights into ways to manage and improve performance. DEA has the ability to analyse relative performance when such weights are not available making it particularly effective in service environments where these weight are not available like hospitals. Therefore - the ability to incorporate multiple inputs and outputs in their natural units without knowledge of the relative weights - makes DEA uniquely suited for evaluating many services like those of hospitals. 
Efficiency level of public hospitals in this study was examined in terms of their ability to use minimum (fixed) quantity of resources to produce as much output as possible (CRS). This is because public hospitals are usually provided with a fixed quantity of resources and are expected to produce as much output as they possibly can. This is an output based measure of technical efficiency score (output orientation) of a health facility. However, it has been reported that the choice of the orientation (input or output orientation) has only a minor influence upon the efficiency scores obtained (Coelli, Prasada, O'Donnel, \& Battese, 2005). Further, a number of iterations were performed to investigate how sensitive efficiency scores are to an increasing number of hospital activities. Second, the difference in efficiency levels of Sub Divisional Medical Centres, Integrated Health Centres and District Hospitals as well as the difference in efficiency levels between Urban, Semi-urban and Rural health facilities were carried out using One-way analysis of variance (ANOVA) method with post hoc comparisons. DEAPv2.1 developed by Coelli (1996) was used to estimate the efficiency scores for public health facilities and SPSSv20 was used to perform the analysis of variance.

Analyses in the study employed secondary data based on the first Public Expenditure Tracking Survey (PETS1) jointly carried out in Cameroon by the World Bank and the National institute of Statistics. The aim of the survey was to collect information on the health sector at the frontline level, including resource use, delivery processes, services, staff and patient behaviour and characteristics. Data were collected using questionnaires administered to health regional delegates, medical doctors, and heads of health centres, health employees and patients (Njong \& Ngantcha, 2013). The current study utilises panel data for 109 health facilities observed for two time periods i.e. 2002-2003.

However, "there exist a lot of controversy regarding the choice of the appropriate input and output variables because of the special characteristics of health industry and the difficulties in measuring the final output of health care provision, The final production outcome of this industry, that is "health improvements", is heterogeneous, multiple and it does not occur in discrete units. Thus, it is difficult to measure and at the same time take into account the quality of the health care service output. Consequently, a significant proportion of variability exists in the chosen input and output sets between different studies" (Maniadakis et al., 2009). However, the inputs and output variables included for this study were selected based on what has been widely used in most empirical works.

Table1.1. Definitions of Variables

\begin{tabular}{|l|l|}
\hline \multicolumn{2}{|l|}{ Variable } \\
\hline \multicolumn{2}{|l|}{ Description } \\
\hline Admissions & \# of inpatients or hospitalizations \\
\hline $\begin{array}{l}\text { Total number of } \\
\text { consultations }\end{array}$ & General medical Consultations \\
\hline length of stay & Days stayed by inpatients in hospital \\
\hline Medical Tests & Includes HIV/AIDS, Urine analysis, other STDs, etc. \\
\hline Births & Sum of deliveries for each hospital \\
\hline $\begin{array}{l}\text { Maternal \& Childcare } \\
\text { Services }\end{array}$ & \# of children less than 5 years consulted and prenatal consultations \\
\hline Transfers out & Referrals out of the health facility \\
\hline Transfers in & Referrals into the health facility \\
\hline Follow up cases & \\
\hline \multicolumn{2}{|l|}{ Input Variables(X) } \\
\hline Administrative Staff & \\
\hline Medical Staff & $\begin{array}{l}\text { Include number of active doctors, Nurses, assistance nurses, care givers and } \\
\text { other qualified medical personnel }\end{array}$ \\
\hline Laboratory Technicians & Includes both laboratory and radiology technicians \\
\hline Beds & \# of available beds \\
\hline Other Staff & \# of active workers other than doctors and nurses \\
\hline
\end{tabular}

Source (Researchers,' 2015) \#= Number

\section{RESUlts}

The aim of the study was to assess the efficiency level of public hospitals in Cameroon. The study specifically employed DEA to estimate the technical efficiency of public hospitals and One way analysis of variance method with post hoc comparison to estimate the differences in efficiency 
Assessing the Technical Efficiency of Public Hospitals in Cameroon: An Application of Data Envelopment Analysis (DEA)

between Sub Divisional Medical Centres, Integrated health Centres and District Hospitals as well as Urban, Semi-urban and Rural health facilities. The following section presents our findings.

Table1.2. DEA Efficiency Scores for Public Hospitals

\begin{tabular}{|l|l|l|l|l|l|l|}
\hline YEAR & \multicolumn{3}{|l|}{$\mathbf{2 0 0 1 / 2 0 0 2}$} & $\mathbf{2 0 0 2 / 2 0 0 3}$ & \multicolumn{1}{l|}{} \\
\hline & CRS & VRS & SCALE & CRS & VRS & SCALE \\
\hline Model 1 & 0.4262 & 0.6398 & 0.702 & 0.4453 & 0.668 & 0.7019 \\
\hline St Dev. & 0.3541 & 0.3821 & 0.3266 & 0.3516 & 0.3598 & 0.326 \\
\hline Efficient & 19 & 49 & 24 & 20 & 46 & 24 \\
\hline Model 2 & 0.499 & 0.7089 & 0.7098 & 0.5224 & 0.7497 & 0.7028 \\
\hline St Dev. & 0.3632 & 0.3481 & 0.3298 & 0.3547 & 0.3152 & 0.3233 \\
\hline Efficient & 25 & 57 & 28 & 28 & 55 & 28 \\
\hline Model 3 & 0.5292 & 0.7407 & 0.7145 & 0.562 & 0.919 & 0.617 \\
\hline St Dev. & 0.3635 & 0.3345 & 0.3204 & 0.3432 & 0.1511 & 0.3507 \\
\hline Efficient & 29 & 62 & 32 & 30 & 82 & 30 \\
\hline Model 4 & 0.5717 & 0.7585 & 0.7467 & 0.6098 & 0.8155 & 0.7517 \\
\hline St Dev. & 0.3551 & 0.3249 & 0.2978 & 0.3273 & 0.2686 & 0.2945 \\
\hline Efficient & 31 & 62 & 37 & 32 & 61 & 35 \\
\hline Model 5 & 0.5908 & 0.8035 & 0.7326 & 0.6099 & 0.8265 & 0.7372 \\
\hline St Dev. & 0.3471 & 0.2794 & 0.3132 & 0.3274 & 0.2536 & 0.3047 \\
\hline Efficient & 32 & 63 & 33 & 32 & 62 & 35 \\
\hline Model 6 & 0.634 & 0.841 & 0.7465 & 0.61 & 0.8441 & 0.7269 \\
\hline St Dev. & 0.3323 & 0.2526 & 0.304 & 0.3274 & 0.2286 & 0.3194 \\
\hline Efficient & 36 & 71 & 40 & 32 & 63 & 35 \\
\hline Model 7 & 0.6719 & 0.8606 & 0.7709 & 0.6769 & 0.8702 & 0.7765 \\
\hline St Dev. & 0.3285 & 0.2442 & 0.2918 & 0.3166 & 0.2198 & 0.2921 \\
\hline Efficient & 41 & 75 & 45 & 38 & 71 & 42 \\
\hline
\end{tabular}

Source (Researchers,' 2015) CRS: Constant Returns to Scale; VRS: Variable Returns to Scale

Table 1.1 presents summary of the results from each of the seven iterations. Worthy of note here are the efficiency scores for model 4 which covers all activities that most health facilities included in our study could possibly engage in. it is observed based on the CRS assumption in 2002 that the average efficiency score was 57.17 per cent with a standard deviation of 0.3551 and 31(28.44 per cent) of the health facilities were efficient. In 2003 under the CRS assumption, the average efficiency score was 60.98 per cent with a standard deviation of 0.3273 and $32(29.36$ per cent) of the health facilities were efficient showing an increase in the number of health facilities assigned to the frontier. The average efficiency score tend to be increasing with an increasing number of hospital activities as shown by the varying efficiency scores for models 1-7. The table also presents corresponding VRS efficiency scores for the same estimations and it can generally be observed that that the VRS efficiency scores are higher than the CRS efficiency scores and more health facilities tend to fall on the frontier under the VRS technology than under the CRS technology

Our findings show that there exists a lot of inefficiency within public health facilities in Cameroon. Considering the results for model 4 , the findings show that the health facilities as a group had costs that were 42.83 per cent higher than they would be, had they all been fully efficient in 2002 and in 2003, the findings also showed that health facilities as a group had cost that was 39.02 per cent higher than it would have been, had they all been fully efficient, implying a decrease in cost between the two time periods. The cost was however lower with the VRS technology

In at least four studies, public hospitals were found to be inefficient, Wouters (1993); Zuckerman, Hadley, and Iezzoni(1994); Ferrier and Valdmanis (1996); Chang, Chang, Das, and Li (2004), Annika, (2008); However, quite a number of studies have shown that public hospitals are more efficient than those in private sector, Ozcan, Luke, and Hakseve (1992); Burgess and Wilson (1996); Koop, Osiewalski, and Steel (1997); Chirikos and Sear (2000); McKay, Deily, and Dorner (2003); Sari (2003) and Tiemann\&Schreyögg (2009) found no significant efficiency differences associated with ownership. It can therefore be concluded here that much is still left to be done.

We herewith performed seven different iterations with varying hospital activities to test the sensitivity of DEA efficiency scores with variations in hospital activities. Following our sensitivity analysis 
results (Table 1.2), it was observed that as more variables were progressively added to the model, (i) an increasing number of hospitals obtained an efficiency score of 1; (ii) the average efficiency score for health facilities was increasing; and (iii) the variance in efficiency scores was decreasing, these findings were consistent with those of Jacobs et al., (2006) and Coelli, Prasad et al., (2005) who have similar findings

\section{Difference in efficiency between Urban, Semi-urban and Rural health facilities}

Table1.4. Analysis of variance by location of health facility

\begin{tabular}{|l|l|l|l|l|l|}
\hline & \multicolumn{3}{|c|}{ Summary statistics of ANOVA } & \\
\hline Type of Health Facility & Mean Efficiency & Standard Deviation & Frequency & & \\
\hline Urban & .73559 & .348952 & 56 & & \\
\hline Semi-urban & .67817 & .339221 & 46 & & \\
\hline Rural & .48616 & .303600 & 116 & & \\
\hline Total & .59075 & .341253 & 218 & & \\
\hline & \multicolumn{1}{|c|}{ Analysis of Variance } & & & \\
\hline Source & Sum of Squares & Degrees of Freedom & Mean Square & F & Prob> F \\
\hline Between Groups & 2.795 & 2 & 1.398 & 13.370 & .000 \\
\hline Within Groups & 22.475 & 215 & .105 & & \\
\hline Total & 25.270 & 217 & & & \\
\hline
\end{tabular}

Source (Researchers,'2015)

A one-way between-groups analysis of variance was conducted to explore the impact of location of health facility on efficiency scores. Health facilities were divided into three groups (Group 1: Urban; Group 2: Semi-urban; Group 3: Rural). There was a statistically significant difference in efficiency scores at $\mathrm{p}<0.05$ for the three groups $[F(2,215)=13.370, \mathrm{p}=.000]$. The actual difference in mean scores between the groups was quite large, as guided by the calculated eta squared(effect size) of .11 [Cohen, 1988]. Post-hoc comparisons using the Tukey HSD test indicated that the mean efficiency scores for Rural(M=.48, $\mathrm{SD}=.30)$ significantly differed from Urban $(\mathrm{M}=.73, \mathrm{SD}=.34)$ and Semiurban $(\mathrm{M}=.68, \mathrm{SD}=.33)$ health facilities; there was no significant difference in efficiency scores between urban and semi urban health facilities.

Efficiency scores for urban health facilities in 2002 taken as a group was 72.27 per cent; 64.13 per cent for semi-urban hospitals and 47.13 per cent for rural health facilities. 15 of the 28 urban health facilities were efficient, 8 of the 23 semi-urban health facilities were efficient while only 8 of the 58 rural health facilities were efficient. In 2003, the average efficiency score for urban health facilities under the CRS assumption was 74.84 per cent, 71.5 per cent for Semi-urban health facilities and 50.1 per cent for rural health facilities; 14 of the 28 urban health facilities, 9 of the semi-urban health facilities, only 9 of the rural health facilities were efficient. The findings show that the health facilities as a group had costs that were, respectively 27.73 per cent, 35.87 per cent and 52.87 per cent for urban, semi-urban and rural health facilities respectively following the CRS assumption in 2002 and in 2003 , the health facilities had costs that were 25.16 per cent, 28.5 per cent and 49.9 per cent for urban, semi-urban and rural health facilities respectively higher than what it would have normally costs them had they been fully efficient.

Our empirical evidence therefore suggests that under either scale assumption, rural health facilities were generally less efficient than semi-urban health facilities and urban health facilities respectively. This can be explained by the large investments made to modernize hospital infrastructure in urban centres, accessibility of health facilities and availability of human resources as most young people tend to prefer working in the urban areas of the country. Urban health facilities also have many patients to attend unlike in the rural areas where most people may prefer to use traditional methods of treating themselves. Weisgrau (1995) and Rizzo(1991) reported that there are a lot of differences between rural and urban markets, first, there is a vast difference in the composition of their respective markets, market competition characteristics in urban markets are notably different from those in rural health care markets; further, rural health facilities are generally smaller with lower occupancy rates, a declining and dispersed geographic patient base, they offer fewer specialised services and very little revenue is generated from patient care in the rural areas. 
Assessing the Technical Efficiency of Public Hospitals in Cameroon: An Application of Data Envelopment Analysis (DEA)

Difference in efficiency between Sub Divisional Hospitals, Integrated Health Centres and District Hospitals

Table1.3. Analysis of variance by type of health facility

\begin{tabular}{|l|l|l|l|l|l|}
\hline & \multicolumn{3}{|c|}{ Summary statistics of ANOVA } & \\
\hline Type of Health Facility & Mean Efficiency & Standard Deviation & Frequency & & \\
\hline CMA & 0.64944 & 0.047773 & 54 & & \\
\hline CSI & 0.46057 & 0.030536 & 108 & & \\
\hline HD & 0.78521 & 0.035261 & 56 & & \\
\hline Total & 0.59075 & 0.023113 & & & \\
\hline & \multicolumn{1}{|c|}{ Analysis of Variance } & & & \\
\hline Source & Sum of Squares & Degrees of Freedom & Mean Square & F & Prob F \\
\hline Between Groups & 4.134 & 2 & 2.067 & 21.025 & .000 \\
\hline Within Groups & 21.137 & 215 & .098 & & \\
\hline Total & 25.270 & 217 & & & \\
\hline
\end{tabular}

Source (Researchers,' 2015), CMA= Sub Divisional Medical Centres, CSI= Integrated Health Centres and $H D=$ District Hospitals

We also employed a one-way between-groups analysis of variance with post hoc comparisons to explore the impact of type of health facility on performance as measured by CRS efficiency scores for model 4. Health facilities were also divided into three groups (Group 1: CMA; Group 2: CSI; Group 3: HD). There was a statistically significant difference in efficiency scores at the $p<0.05$ for the three groups $[F(2,215)=21.025, \mathrm{p}=.000]$. The actual difference in mean efficiency scores between the groups was quite large, as guided by the calculated eta squared(effect size) of .16 [Cohen, 1988]. Post-hoc comparisons using the Tukey HSD test indicated that the mean efficiency score for CMA $(\mathrm{M}=0.65, \mathrm{SD}=0.05)$ was significantly different from that of CSI $(\mathrm{M}=0.46, \mathrm{SD}=0.03)$; and $\mathrm{HD}$ $(\mathrm{M}=0.78, \mathrm{SD}=0.03)$; $\mathrm{CMA}$ did not significantly differ from HD.

In 2002, 10 of the 27 Sub Divisional Hospitals were efficient; only 8 of the 54 Integrated Health Centres were efficient and only 13 of the 28 District Hospitals were efficient under the CRS. In 2003, 10 of the Sub Divisional Hospitals were efficient, 10 of the integrated Health Centres were efficient while 12 of the District Hospitals were efficient. The average efficiency shows that Integrated Health Centres were less efficient for the two years than Sub Divisional Hospitals and District Hospitals respectively. Cost analysis revealed that in 2002, Sub Divisional Hospitals, integrated health Centres and District hospitals incurred cost of up to 36.31 per cent, 56.29 per cent and 23.15 per cent respectively higher under the CRS than it would normally have been if they were efficient. It was also found that in 2003, Sub Divisional Hospitals, Integrated Health Centres and District hospitals incurred extra cost of 33.81 per cent, 51.59 per cent and 19.81 per cent under the CRS assumption. More attention should therefore be directed towards improving the efficiency level of public health facilities as this will lead to a lot of savings on the part of hospitals.

\section{Conclusion}

This study investigated the efficiency level of public hospitals in Cameroon using panel data for 109 health facilities covering a period of two years (2002-2003). Property right theories and agency theories were reviewed as these theories help explain the performance of public institutions. The study specifically employed Data Envelopment analysis to estimate the technical efficiency of public hospitals in Cameroon and one way analysis of variance test with post hoc comparisons to estimate the difference in efficiency between hospitals by type(Sub Divisional Medical Centres, Integrated Health Centres and District Hospitals) and by location(Urban, Semi-urban and Rural Health Facilities).

The efficiency levels of the hospitals were examined in terms of their ability to use minimum (fixed quantity) of resources to produce as much output as possible. This is because public hospitals are usually provided with a fixed quantity of resources and are expected to produce as much output as they possibly could. This is an output based measure of technical efficiency score (output orientation).

In order to strengthen the performance of hospitals in their provision of healthcare services in Cameroon, policy makers need information on efficiency which shows how well the health facilities are using the resources. This study has shown how DEA methods can be applied to gain insight into 
variation in efficiency over time. The findings provided technical efficiency scores in Urban, Semiurban and Rural areas as well as Sub Divisional Medical Centres, Integrated Health Centres and District Hospitals for two years. These combined efficiency scores indicated which health facilities and at what location are more and less efficient in providing health services

Our results revealed that there is mass inefficiency within Cameroons public hospitals and as a consequence, health facilities incur higher cost of operation than if they had been fully efficient; further, CRS efficiency scores were generally lower than VRS efficiency scores, an increasing number of hospitals were obtaining an efficiency score of 1 with an increase in hospital activity; the average efficiency score for health facilities was increasing and the variance in efficiency scores was decreasing with an increasing number of hospitals activities. Rural health facilities were generally less efficient than semi-urban and urban health facilities while Integrated Health centres were less efficient than Sub Divisional Medical Centres and District Hospitals respectively.

From the results, we suggest that the Ministry of Public Health should put in more efforts geared towards ensuring an increase in the overall efficiency by developing policies and procedures to control the wastage of valuable input resources, training and recruiting more qualified medical personnel. While the government continue to explore other alternative health financing options as indicated in the Vision 2035, efficiency improvement should be considered as one of the strategies for mobilizing more domestic resources.

\section{REFERENCES}

Álvaro, A., \& Fique, J. P. (2011). Evaluating Hospital Efficiency Adjusting for Quality Indicators: An Application to Porturguese NHS Hospitlas. FEP Working Paper.

Amy, P., \& Robert, R. (2006). Efficiency of Thai provincial public hospitals after the introduction of National Health Insurance Program. School of Economic Sciences, Washington State University.

Annika, F. (2008, February 27). Cost and Technical Efficiency of German Hospitals: Does Ownership Matter? Ruhr Graduate School in Economics, Ruhr-Universit"at Bochum.

Beri, P. B. (2015). Assessment of Efficiency and Productivity in the Provision of Healthcare Services in Cameroon: The Case of Public Hospitals. An Unpublished Dissertation Submitted to the Faculty of Social and Management Sciences of the University of Buea in partial fulfilment of the Requirements for the Degree of Master of Science (M.Sc.) in Economics.

Coelli, T. J. (1996). A Guide to DEAP Version 2.1: A Data Envelopment Analysis(Computer) Program. Centre for Efficiency and Productivity Analysis(CEPA) Working Papers.

Coelli, T. J., Prasada, R., O'Donnel, C., \& Battese, G. (2005). An Introduction to efficiency and Productivity Analysis. New York, United States of America: Springer.

Jacobs, R., Smith, P. C., \& Street, A. (2006). Measuring Efficiency in Health Care: Analytic techniques and Health Policy. New York: cambridge university press.

Kamgnia, B. (2006). Use of health Care services in Cameroon. International Journal of Applied Econometrics and Quantitative Studies, vol 3, No2, 53-64.

Kathleen, E. M. (1989). Agency Theory: An Assessment and Review. Academcy of Management Review, Vol.14(No.1), 57-74.

Maniadakis, N., Kotsopoulos, N., Prezerakos, P., \& Y fantopoulos, J. (2009). Health Care Services Performance Measurement: Theory, Methods and Empirical Evidence. European Research Studies, Volume XII, Issue (3), 151-170.

Marsha, B., Govind, H., Lipson, R. A., \& Aultman, C. (2008). Global Perspectives on Economics and Health Care. Jones and Bartlett Publishers.

Meryem, D. F. (2000). Efficiency and Productivity Growth in the European Airlines Industry: Applications of Data Envelopment Analysis, Malmquist Productivity Index and Tobit Analysis. Thesis Submitted for the Degree of Doctor of Phylosophy at the University of Leicester.

Molem, S. C. (2008). Decentralisation of Health Care Spending and HIV/AIDS in Cameroon. Governing Health Systems in Africa.

Murray, C. J., \& Frenk, J. (2002). A WHO Framework for Health Systems Performance Assessment.

Nazgul, M. (2011). Efficiency Analysis of the Health Centres in Karaganda oblast, Kazakhstan: Data envelopment and Malmquist index analysis. UMEA, University. 
NIS. (2010). Second Survey on the Monitoring of Public Expenditures and the Level of Recipients Satisfaction in the Education and Health Sectors(PETS2). Yaounde: National Institute of Statistics.

Niskanen, W. A. (1975). "Budgets and Politicians". Journal of Law and Economics. Economic Analysis of Political Behavior: Universities-National Bureau Conference Series, Vol.18 No.3, 617-643.

Njong, A., \& Ngantcha, T. J. (2013). Institutions and Leakage of Public Funds in the Cameroonian Healthcare Delivery Chain. Journal of African Development, Vol.15 No.1, 19-43.

Nunamaker, T. (1985). Using data envelopment analysis to measure to measure the efficiency of nonprofit Organisations: A critical evaluation. Journal of managerial and Decision Economics, 5058.

Peacock, S., Chan, C., Mangolini, M., \& Johansen, D. (2001, July). Techniques for Measuring Efficiency in Health Services. Productivity Commission Staff Working Paper.

Tiemann, O., \& Schreyögg, J. (2009). Effects of Ownership on Hospital Efficiency in Germany. Business Research: Official Open Access Journal of VHB, 115-145.

Williams, A. (1988). Priority setting in public and private health care. A guide through the ideological jungle. Journal of Health Economics, 173-83.

Xu, X., \& Jeffrey, S. R. (1998). "Efficiency and Technical Progress in Traditional and Modern Agriculture: Evidence from rice Production in China". Agricultural Economics, 157-165.

\section{AUTHORS' BIOGRAPHY}

Professor Molem Christopher Sama, is Professor of Economics and Head of Department for Economics and Management, University of Buea, Cameroon. His research interests include Development Economics and Health Economics.

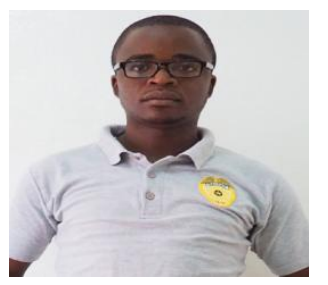

Beri Parfait Bihkongnyuy, is a graduate teaching and research assistant in the Department of Economics and Management, University of Buea. His major research interest includes Development Economics, Health Economics, Economics of Education and Econometrics 